\title{
The technological invention of disease
}

Bjørn Hofmann University of Oslo, Norway

\begin{abstract}
Technology has come to play a profound role in medicine since the middle of the 19th century, and many scholars have analysed the role of technology in medicine. Parallel to this development there has been a comprehensive debate on the concept of disease. This article combines these fields and investigates the influence of technology on the concept of disease. With reference to the literature it tries to elaborate an explicit account of the constitutive role of technology in relation to the concept of disease. It will be argued that technology constitutes the concept of disease in three profound ways. Firstly, technology provides the physiological, biochemical, and biomolecular entities that are applied in defining diseases. Secondly, it establishes the way we try to gain knowledge of disease and the way we recognise disease in practice. Technology constitutes the signs, markers and end points that define disease entities and it strongly influences the explanatory models of disease as well as medical taxonomy. Thirdly, technology establishes how we act towards disease: thorough diagnosis and treatment technology establishes the actions that constitute the concept of disease. Altogether, this constitutive technological influence on the concept of disease is considered as a technological invention of disease.
\end{abstract}

(F Med Ethics: Medical Humanities 2001;27:10-19)

Keywords: Technology; concept of disease

\section{Introduction}

There has been a diverse and complex debate on the concept of disease. It has been debated whether "disease" is a theoretical or a practical concept. ${ }^{1-5}$ Furthermore, the logical, the ontological and the normative status of the concept of disease have been widely discussed.

Parallel to the debate on the concept of disease, there has been a debate on the role of technology in medicine. There is unanimity that technology plays an important role in the development of medical theory as well as clinical practice. Technology has become the driving force of medical development. It has changed medical knowledge as well as its practice. The discovery of bacteria, the development of penicillin, and the elaboration of the diagnostic and therapeutic armamentariumelectrocardiographs (ECG), x-rays, magnetic resonance imaging (MRI), endoscopy and genetic and pharmaceutical products-have all played an evolutionary role in medicine over the last two centuries.

Although both the concept of disease and the role of technology in medicine are central issues in the philosophy of medicine, only a few scholars have extensively addressed the question of how technology influences the concept of disease. The objective of this article is to elaborate, from the existing literature, an explicit account of the constitutive role of technology in relation to the concept of disease.

There might be many ways in which technology influences health care in general and the concept of disease in particular. Firstly, according to a common account, technology has eradicated many diseases, reduced the prevalence of others and improved the health of the human race. Technology has great potential for reducing disability and avoidable death, improving the quality of life and prolonging lives of good quality. ${ }^{6}$ That is, technology alters the occurrence of disease. Secondly, it has been argued that technological development alters the physical and social environment of humanity, creating new diseases. Life in modern urban societies causes man to develop new diseases. $^{7}$ Thirdly, modern medicine has become dependent on and altered by the technical armamentarium it applies. It has changed the content and configuration of its knowledge. Both in theory and in practice, technology appears constitutive of medical activity and its basic concepts.

Only one of these three perspectives will be addressed in this study. The perspective of technology eradicating disease is an epidemiological matter and will not be pursued here. The second one, analysing how technology changes the human environment and thereby the distribution and definition of diseases, is an indirect perspective. Even though there might be a plausible explanation of how technology has influenced the human environment, this does not necessarily explain the emergence of new diseases. This matter will therefore not be pursued any further. The third perspective, however, represents the strongest claim. If it can be argued that technology provides the basic phenomena which define disease and does indeed generate and form medical knowledge and action, there has to be an essential relation between technology and the concept of disease. The objective of this review is to investigate such a possibility. This will be done with reference to the literature on the concept of disease and on technology in medicine.

\section{An opening remark on technology}

Before we enter the detailed discussion on how technology constitutes the concept of disease, it is important to be clear what is meant by technology. A plausible definition of technology might be that it is 
the complex of devices, methods and organisations applied in human purposive activity. Both in terms of devices, methods and organisation, technology today is integrated in modern medicine. A defibrillator (heart starter) is not just a box with wires, electrodes and electronic components (device). It is a defibrillator because it is a methods of medical resuscitation applied in an organisation of health care. This definition of technology stresses the significance of technology for different levels of health care, and accordingly the term "technological medicine"emphasises the constitutive role of technology in modern medicine.

Let us then start with the role of technology in establishing the entities that are applied in defining disease.

\section{The technological constitution of the entities defining disease}

Technology provides the entities and events that are applied in defining diseases both in diagnostics and in treatment, in clinical practice and in research. The pathological morphology, chemical substances, biochemical agents and biomolecular sequences studied in research, detected in diagnosis and manipulated in therapy are grounded in technology. "It is the x-rays, the laboratory studies, the pathology reports ... which are taken to constitute the central phenomenon [sic] of disease." Technology provides the basic entities for defining disease. Light microscopy establishes basic structures, such as the cell, whereas stains and cultures constitute viral and bacterial agents, and electron microscopy defines a range of diseases.

The QRS-complex, the echodoppler image and its corresponding indices, the scintigram and angiogram, establish a wide range of cardiac diseases which are generated by technology such as the electrocardiograph, ultrasound machine, gamma camera and x-ray modality. Entities such as Helicobacter pylori, urea, cholesterol, and deoxyribonucleic acid (DNA) are basic to the definitions of diseases such as peptic ulcer, renal insufficiency, cholesterolaemia, and Huntington's disease.

Evans argues that technology constitutes the aetiological agents that define disease. For example, the technology which cultivates and identifies bacterial culture has led to the discovery of most bacteria causing diseases: The development of fluorescent antibodies resulted in the discovery of $M$ pneumoniae, and the aetiology of infectious mononucleosis. Furthermore, the growth of human B and $\mathrm{T}$ lymphocytes in suspension cultures led to the discovery of several important groups of viruses. $^{9}$ In this manner, technology constituted a number of disease entities.

Correspondingly, the phenomena constituting epilepsy were in antiquity conceived as being humoral and spiritual (the sacred disease). Through technology, for example, electroencephalography and chemical analysers, the constitutive phenomena of epilepsy have come to be the electrical activity of the brain and the paroxysmal function of cerebral nerve cells.
Furthermore, we do not perceive entities such as Helicobacter pylori and DNA directly, but rather, they are provided by technology. We have no access to the time-delays ( $\mathrm{T} 1$ and $\mathrm{T} 2$ ) constituting the magnetic resonance image except through the MRI machine. The ECG providing the signs of various cardiac diseases does not exist independently of the electrocardiograph. They are constituted by the armamentarium itself.

Hence, the basic phenomena and entities applied to define many central diseases are provided by technology. Technology, however, also influences the way we detect, identify and interpret these phenomena. That is, technology strongly influences the content and formation of medical knowledge. This will be investigated in the following section.

II. The technological knowledge of disease Technology constitutes medical knowledge in several ways: It establishes the signs, markers and end points that define the disease entities. Furthermore, technology strongly influences the explanatory models of disease and the way medical knowledge is organised (its taxonomy).

\section{Signs $^{10}$}

Modern medicine relies on paraclinical signs for defining and detecting disease ${ }^{11}$ For example blood pressure and venous plasma glucose concentration define diseases such as hypo-, and hypertension and diabetes. A variety of cardiac conditions are defined by specific ECG patterns, ultrasound Doppler flow and tissue stress measurements, and radiographic morphology. Paraclinical signs that define disease might be abnormalities of morphology, physiological aberrations, biochemical defects, genetic abnormalities, ultrastuctural abnormalities and aetiological agents. ${ }^{12}$

Such paraclinical signs are detected with chemical analysers, x-ray-modalities, ultrasonic devices, haemodynamic monitors, computed tomography (CT)-, MRI-, and PET-scanners. Furthermore, they are manipulated by dialysis machines, lasers, diathermy, anaesthiological devices and drugs of various kinds. In this manner technology founds the paraclinical signs that define disease. One important reason for the constitutive role of these paraclinical signs is that they can be reproduced. "The electrocardiograph began to serve as the objective graphic method for establishing firmly and convincingly the clinical diagnosis of coronary heart disease."13

\section{Technology renders the signs of disease reliable.}

However, not only paraclinical signs are established by technology. Clinical signs earlier investigated by manual means are now tested by technology. "And we are even happier when these pathognomonic signs or specific tests are revealed by the exact instruments of a clinical laboratory, by x-rays or by the whole gamut of electrical recording 
machines." ${ }^{14}$ The perception of blood colour in a wound has been substituted by oxygenation measures, for example, $\mathrm{pO}_{2}$ and $\mathrm{SaO}_{2}$.

Moreover, technology is not restricted to founding the clinical and paraclinical signs of disease. Technology is also applied to detect symptoms and syndromes. ${ }^{15}$ The importance of technology in the generation and formation of knowledge in medicine has led to the application of technological tests in the detection of symptomatic diseases and syndromes as well. In fact technology has become the gold standard for assessing and evaluating such conditions. Lung infarction is an example. Here pulmonary angio and lung scintigraphy have been applied as a standard for diagnosing this symptomatic disease. ${ }^{16}$

Furthermore, the set of technological tests is constitutive of how physicians conceive the symptoms of the patient. Chest pain of a certain kind immediately implies an ECG with a focus on the ST-segment. In medical practice the symptoms are transformed into paraclinical signs and tests. Symptoms gain significance only as projections of signs. Technology directs their significance and the way they are interpreted and acted upon.

Hence, technology influences the conception of symptoms in two ways. Firstly, technology is developed to detect symptoms. Secondly, the subjective experience of the patient is projected onto paraclinical signs and tests.

\section{Markers and risk factors of disease}

In many cases the signs that define diseases are not accessible. However, various markers are applied to detect and identify them. For instance, changes in DNA are markers or risk factors for Alzheimer's disease (chromosome 1, 14, 19 and 21). ${ }^{17}$ For such diseases neither signs nor symptoms are detectable early in the development of the disease. Genetic markers, however, might indicate a disposition to them. Such markers are applied to identify and distinguish disease entities. As with paraclinical signs, disease markers are provided and founded by technology. Advances in technology facilitate the identification of new markers that will be treated as disease. ${ }^{18}$

Thus, the technological constituted signs and markers are basic to the demarcation of disease. They define disease entities and are applied to recognise disease in the particular case, and as such provide a technological semiology of disease.

\section{Technological end points}

The signs and markers of disease also represent the measure of what is to be altered in order to make the patient healthy again. The general belief in the existence of basic phenomena such as cells, calcium and potassium concentrations, or signs such as ST-segment displacement and markers like trisomy 21 , causes physicians to try to influence and manipulate them. They become end points of medical treatment. The end point of the treatment of hypertension and cholestorelaemia is the blood pressure and the level of cholesterol in the blood. The aim of genetic engineering is to repair or exchange defective DNA sequences, for example in persons showing markers of Huntington's disease. Hence, technology defines the signs and markers to be detected, studied and manipulated in medicine and thereby it also constitutes the end points of medicine. ${ }^{19}$

\section{Technological explanation of disease}

It has been argued that there are important conceptual ties between different forms of causal thinking and particular views of what diseases are..$^{20-22}$ Throughout history disease has been explained within different causal frameworks. Disease has been conceived as an imbalance of the humours (Hippocrates, Galenus), as a disturbance of the morphological structure of the elements of the body, such as its organs (Morgagni), tissues (Bichat) or cells (Virchow), and as an error in the base pair sequence in deoxyribonucleic acid (DNA). "Forms of explanation influence how a disease is conceptualised through the conceptual schemes the explanations presuppose." ${ }^{23}$ Hence, the explanatory language of medicine is constitutive of the concept of disease. ${ }^{24-25}$ In addition, as argued, this language is today formed by technology, and it is technology which constitutes its expressions, measures and aims. In other words, the causality of disease is limited by its frame of reference ${ }^{26}$ which is in turn technological methodology. ${ }^{27}$ The explanatory models of disease and its causality are constituted by technology. ${ }^{9}$

Moreover, technology has not only constituted the models of disease. It has influenced the models of humanity itself. ${ }^{28-29}$ The application of technology in medicine, successfully detecting, identifying and treating disease, has made it a model for human physiology:

"From the 19th century onward there has been a succession of more sophisticated models, all based on the latest fashionable technologies. The ear, originally a harp (according to Helmholtz) became a telephone and is now known to be an advanced stereophonic hi-fi system. The brain, viewed by Descartes as a hydraulic network, has since been recognised as a telephone exchange, a computer and, more recently, a holographic data storage system. The eye was once a telescope, then a simple camera and is now known to be a very elaborate camera, with the original zoom lens and throughthe-lens exposure meter, producing instant threedimensional pictures in colour on re-usable film." ${ }^{30}$

Technology is not only constitutive of the models of health and disease. It provides also for their metaphors. Furthermore, with the application of artificial organs such as pacemakers, cochlear implants and advanced limb prosthesis, technology becomes a part of humanity's physical existence, that is, there is a fusion of human being and technology. ${ }^{31}$ Hence, technology constitutes the explanatory models of disease and its symbolism, in 
addition to establishing the signs and markers that define diseases.

\section{Technological taxonomy}

Furthermore, the organisation of medical knowledge is influenced by technological innovation. Progress in science and technology changes the classification of disease. This is explicitly stated in the introduction to the International Classification of Disease. ${ }^{32}$ Since the time when technology began to impact on medicine, the number of disease entities has increased coherently with technological development which, whilst typically gauged by qualitative judgments, is generally believed to follow an exponential curve. ${ }^{3}$

The influence of technology on medical taxonomy has been commented on in various ways Jensen claims that classification does not result from the nature of disease, but from the apparatus of treatment. ${ }^{34}$ Wulff correspondingly argues that the development of treatment strongly influences the classification of disease. ${ }^{35}$ As will be argued later, technology is constitutive of medical treatment. Hence, a medical taxonomy founded on existing treatment must be influenced by technology.

According to Feinstein the classification of diseases seems to follow three main organising principles. ${ }^{36}$ Firstly, diseases are classified according to clinical manifestations. Secondly, they are classified according to entities causing these manifestations. Thirdly, diseases are classified according to patterns and events following the clinical manifestations. The main argument so far is that the manifestations, the causal entities and the resulting patterns and events are constituted, detected and identified by technology. It follows from this that the organisation of medical knowledge is also established by technology.

The influence of technology on the classification of disease appears in several ways. Firstly, technology creates new disease entities. Secondly, it changes existing disease entities. Thirdly, technology differentiates existing disease entities.

NEW DISEASE ENTITIES

There are numerous examples of new disease entities generated by technological innovations. To cover even a fraction of them is beyond the scope of this study. Some examples will be discussed to illustrate the point. It has been argued that the invention of the sphygmomanometer established hypertensio arterialis. ${ }^{37}$ Correspondingly, the electrocardiograph revolutionised the analysis of heart diseases, resulting in several new disease entities. For example, the clinical entity atrial fibrillation was established by the ECG. ${ }^{38-39}$

The case of electrocardiography can be applied to illustrate another important aspect of the technological generation of new disease entities. It also constituted conditions such as silent ischaemia. The electrocardiograph revealed that many patients had similar changes of their ECG when undergoing stress-testing as patients with angina, and that such changes predicted an increased risk of heart disease. In this way the technological method established disease without the patient feeling ill. Hence, it was the technological test that defined and detected disease and that initiated medical activity and not the subjective experience of the patient.

In this way technology has replaced the traditional meaning of disease, for example, bodily pain (dolor corporis), suspension of joy (intermissio voluptatum), and fear of death (metus mortis)..$^{40}$ Disease has become independent of the subjective experience of the person, and technology has endorsed a new range of disease entities: asymptomatic diseases. ${ }^{41}$ The development of molecular biology is a clear example of this. A great number of new disease entities are based on genetic abnormalities. A variety of genetic tests can detect diseases where the person tested does not feel ill.

How technology has made medicine less dependent on the subjective experience of the patient will be discussed in further detail later. Here it has been argued that technology constitutes the classification of new disease entities and a wide range of them are asymptomatic diseases.

\section{TECHNOLOGICAL CHANGE OF DISEASE ENTITIES}

When development in technology changes the phenomena that are applied to define disease and the explanatory models of medicine, this correspondingly affects the classification of disease entities. ${ }^{42-43}$ "[T] he concepts used in a given field of scientific inquiry will change with the systematic advances made in that field: the formation of concepts will go hand in hand with the formulation of laws and, eventually, of theories." ${ }^{44}$ Hence, disease entities alter with the advances of technology. They develop according to "the gradual adoption of characteristics derived from more precise fields of inquiry" and the "new definition tends gradually to displace the old". ${ }^{45}$ A "more precise field of inquiry" refers to the technological approach to medicine, for example the introduction of the electrocardiograph, resulting in people "beginning to die of myocardial infarction rather than indigestion" ${ }^{46}$

Disease terms such as "epilepsy" and "dropsy" have been applied in medicine since ancient times. Their meaning and extension, however, have changed. The name "dropsy" was replaced by "Bright's disease", which was then exchanged for "nephritis", and lately, has become "end stage renal disease" (ESRD).

Changes in conceptual framework, for example the prevailing entities, theories and tests, result in alteration of disease entities. For example diabetes has been conceived of as a condition caused by excessive salt (Paracelsus), excessive food, sex or alcohol (Amatus Lusitanus), as a disturbance of the nervous system (Cullen), as a disturbance of the nutrition of the liver (Bernard), atrophy of the pancreas (1788-1910), and hydropic degeneration of the islets of Lagerhans (Opie) ${ }^{48}$ Today diabetes is considered to be the result of infectious agents. Similarly, infectious diseases were earlier classified 
according to their respective organs. Today they are classified separately. The technological detection of viral and bacterial specimens establishes the category: infectious diseases.

Hence, technological development in medicine changes the definitions and taxonomy of disease entities. $^{123249}$

\section{DIFFERENTIATION OF DISEASE ENTITIES}

A third way in which technology has contributed to the development of disease entities is through the differentiation of existing entities. What was once reckoned to be one disease entity has, through the development of technology, evolved into a multitude of different diseases, for example what was once called acute respiratory disease developed into many different infectious and chronic diseases entities. The only way both to differentiate and properly detect the various entities was by the use of proper laboratory technology. ${ }^{50}$ Diseases, previously diagnosed in only a vague manner, have now been rendered less ambiguous by technological means and can thus be clearly differentiated.

For example, angiography, echodoppler and tissue-velocity-imaging have resulted in an extended classification of myocardial infarction. The application of the tank respirator in the 1950s established the differentiation between intercostal and bulbar polio. ${ }^{51}$ In the case of intercostal polio the treatment with a respirator had an effect, but not in the case of bulbar polio.

So, technology has altered medical taxonomy: It has constituted new disease entities and changed and differentiated existing entities.

\section{From subjective symptoms to objective signs}

Technology has thus become constitutive in defining, classifying and identifying disease entities. It has been argued that technology makes diagnosis and treatment objective and reliable. It facilitates direct access to the disease. "Ophthalmoscope, bronchoscope, etc allow him [the physician] a direct view of the conditions of many parts." ${ }^{52}$ This, however, has reduced the epistemological importance of the individual person for the concept of disease; it has reduced the importance of the subjective experience of the patient.

Before the eighteenth century medicine was based on the patient's narrative of the symptoms. In addition to this subjective portrait of the illness, the physician observed the patient's appearance and behaviour as well as any signs of disease. During the eighteenth and nineteenth centuries medical instrumentation enabled and extended the physical examination of patients which made the physician less dependent on subjective narration. ${ }^{53}$

"In the nineteenth century, a separation between the subjective history of the patient and the objective examination by the physician became noticeable. The objective signs of percussion and auscultation were the early core of examination temperature curves and the result of the ever increasing tests and special examinations, followed. Thus the case history has come to incorporate all the data obtained through the scientific progress of medicine." 50

With the stethoscope the physician could "listen to the disease directly". Measuring blood pressure gave an "objective account" of the internal conditions in the patient. The introduction of machines such as the ECG, x-ray, and chemical laboratory analysers during the nineteenth and twentieth centuries further enhanced the objectivity of medicine..$^{54}$ "Experimental medicine enables the physician to interpret his findings so as to translate the language of symptoms and tests into the language of physiological processes. Here then is a scientific approach to individual sickness." ${ }^{55}$ Furthermore, the doctor had to ignore the obvious symptoms and signs. "Fever and joint pain were the symptoms that frequently brought patients to doctors. Yet, it was just these obvious complaints that physicians were asked to ignore in favour of potential dangers, often unperceived by the patient, that had to be detected through new technological devices. ${ }^{.56}$

In addition to removing the errors introduced by subjective patients, technology also reduced the risk of error in physicians' judgments. Technology freed medicine from the subjective, individual and emotional, which confused the conception of "the real objective disease". "Twentieth-century technology with all its progress had tended to push the human dilemmas of illness out of the doctor's thoughts, and replace them with laboratory facts derived from tests on the patient's body." ${ }^{\text {"57 }}$ Whereas the physician earlier was dependent on narration and clinical signs, he has nowadays come to rely on pathogenetic and aetiological signs.$^{58}$ Technology has guided medicine from basing its knowledge on symptoms to basing it on clinical signs, and from them to paraclinical signs and markers.

There has been "a detachment from the suffering of [the] patient". ${ }^{59}$ This detachment is made explicit in the technological concept of disease. The capacities of technological medicine have replaced the individual patient as the epistemological basis of the disease concept. This has urged critics to maintain that medicine has become a "stranger medicine" $" 60$ and that technology has altered the patient's experience of being ill, for example that the x-ray image becomes part of the patient's illness. ${ }^{61}$

\section{The technological gaze on disease}

One way to epitomise how technology has influenced the content and formation of medical knowledge, is through the notion technological gaze. As argued, technology constitutes the signs, markers and end points that define disease entities, it strongly influences the explanatory models of disease and the way that medical knowledge is organised, ie medical taxonomy. Hence, technology provides medicine with a new and radically different semiology. ${ }^{62}$ 
Technology constitutes the categories of the medical gaze. It translates the physiological events into "the language of machines". ${ }^{63}$ "Innovations transform the perceptual experiences ... of those who use them." ${ }^{\prime 64}$ Medical technology creates what the physician, the technician or the researcher sees. And they see what they are looking for: disease. "The technology mediates between the seer and the seen and what is seen becomes largely constituted by technology. This is why practices change with the development of new technologies." ${ }^{\prime 65}$ As argued, technology even transfers subjective symptoms into the realm of paraclinical signs.

The way we perceive diseases, name them and talk about them is dependent on technology. Technology has become constitutive of the medical gaze and added to medical language. "The technical elucidation of somatic disease pictures has steadily added to and refined our vocabulary of disease entities." 66 "Roentgenolography, endoscopy, biopsy, and unprecedented surgical operations became available, allowing clinicians to observe specific representations of morbid anatomy during life. With these new techniques of observation, the clinician could now classify evidence directly.", Hence, the medical gaze and the way we talk about this medical perception have altered with technological development. The change in medical gaze can be recognised in medical language. "[T]he question of chest pain has been changed to the question of coronary heart disease, which is changed to the question of coronary artery disease ... . [C] hanging the question is a result of available technology., ${ }^{\prime 67}$

Before the nineteenth century dropsy was characterised and recognised by symptoms such as diminished urine and swollen legs. During the 1840 s, patients with the same symptoms came to have Bright's disease. The technique of detecting albuminuria had, together with the recognition of different textures of autopsied kidneys, established a new disease entity. Furthermore, the application of the light microscope and cryoscopy during the 1850 s established the disease entity (glomerulo-) nephritis. In the 1970s the development of the dialysis machine and the method of transplantation established end stage renal disease (ESRD) as a disease entity. ${ }^{47}$

Each new technology represented a new perspective and a new language which were distinctively different from the perspective and the language of the patients. Technology changed the physician's perception and made disease the physician's property, but at the same time removed him or her from it. "The nephrologist has ... lost touch literally with the diseased kidney itself ... [he] now sees kidneys only microscopically, a biopsied bit at a time, or views shadowy reniform images on an ultrasound screen., ${ }^{\prime 68}$ Or in other words, there is an electronic narration of disease. ${ }^{69}$

This technological gaze in medicine has been criticised because it fits the illness of the patient to the skills of technology. As H Spiro, a Yale professor in medicine, remarked:
"The worst problems come when the doctor fits the patients to his skills, something which is true for all professions. A woman comes to a gastroenterologist and gets a sigmoidoscopy, a barium enema and a high fibre diet. Going to a gynecologist, she runs the risk of laparoscopy and of losing her uterus if she continues to complain. ... I know that the minute I see the x-rays of the patient, before looking at the patient or before working on him, I will fit the patient's story into whatever the x-rays or other images are showing me.”20

Altogether, medical knowledge is constituted by technology: technology constitutes the signs, markers and end points that are applied to define disease entities, it strongly influence the explanatory models of disease and the way that medical knowledge is organised. Hence, there is a technological gaze in medicine.

\section{The practical formation of the disease concept}

In addition to this essential role of technology in the formation of medical knowledge and the constitutive role of technology to the (physiological, biochemical, biomolecular and morphological) entities that are applied to define disease, there is a pragmatic influence on the conception of disease. The concept of disease is defined by its use ${ }^{70}$ and the use of the term "disease" is constituted by the application of histopathological and chemical analysers, CT, MRI and PET scanners, and ECG, electroencephalographs (EEGs) and electromyographs (EMGs). Hence, technology does not only constitute the concept of disease by its subject matter and by medical knowledge, but also through medical practice. This practical formation of the disease concept will be investigated in the following sections.

\section{The technological constitution of medical action}

Conceptualising disease is motivated by the purpose of medicine: to help the patient. ${ }^{35}$ The concept of disease is formed by the physician's capacity for action. This seems to create an obligation: "Choosing to call a set of phenomena a disease involves a commitment to medical interaction." The need for medical intervention causes certain conditions to be perceived and classified as disease. $^{72-73}$ The perspectives of the medical gaze and the concepts of medical language have an aim: medical action.

\section{DIAGNOSIS}

Blume has pointed out the special importance of technology for diagnosis: "Through a variety of processes, physicians have been led to attach more and more significance to the evidence provided by machines. This is nowhere more evident than in the field of diagnostics." ${ }^{74}$ The diagnostic methods give access to the signs and markers that define the disease entities. They provide the means to recognise 
the entities in clinical practice. The diagnostic methods of modern medicine are founded by technology, which ties the concept of disease even closer to technology.

In this way, technology comes to constitute an operational definition of disease where the concept of disease is defined with reference to a particular operational test. ${ }^{44} 75$ "Disease" is a term that applies to all those cases where a given technological test yields a specific outcome. Diabetes mellitus is defined as a fasting glucose concentration of the blood plasma above a given level. Hence the practical identification of disease is given by the technological test.

Furthermore, it has been argued that the practical ability to detect phenomena in the human body has changed the meaning of these phenomena. Detectable phenomena, such as the electrical activity of the heart disclosed by ECG, gained importance by their correlation to various pathologies. The electrocardiogram "transformed the meaning of the heart's electrical activity". ${ }^{76} \mathrm{Al}$ though this electrical activity was already known to a certain extent at the end of the 19th century, it had no pathological significance. With the development of the electrocardiograph the electrical activity of the heart gained significance and constituted disease entities. Correspondingly, disease entities that earlier were detected using one technological method alter diagnosis with the emergence of new technology. Congenital heart disease was earlier detected by angiography, but is now diagnosed by ultrasound Doppler and tissue stress measurements. A change in diagnostic method has altered the conception of the disease.

It might be argued that there are a vast number of disease entities where there are no technological tests. Hence, technology cannot be constitutive of the definition and diagnosis of the disease entities. Even new disease entities, for example whiplash and fibromyalgia have no corresponding technological tests. These examples, as with other symptomatic diseases, do not, however, weaken the argument for the technological diagnosis of disease. On the contrary, these cases are controversial in medical literature. They are considered as borderline cases and classified as syndromes. Nontechnological disease entities are low-status diseases $^{77}$ precisely because they are not technologically testable and treatable. ${ }^{78}$

\section{Treatment}

In practice the fundamental role of technology in relation to the concept of disease is not limited to diagnosis. There is also a therapeutic constitution of disease. It has been claimed that a technological treatment of disease is the result of a technological conception of disease. A mechanically or technologically structured concept of disease requires a mechanically or technologically structured therapy. ${ }^{79} 80$

However, the relationship between technology and treatment might also be conceived in a reverse mode: technological treatability itself constitutes disease. It has been argued that it is not the concept of disease that decides whether something is treated or not, it is the treatability that makes something a disease. . " ... it is not really the presence of a disease that is crucial, but the fact that some medical intervention may be beneficial and that it is within the physician's power to help the patient." 80 "There is little to be gained from labelling [something as disease] if not much can be done once the label has been arrived at." ${ }^{\prime 1}$ Taylor recognises how therapeutic concern constitutes the concept of disease. ${ }^{82}$ Disease is what causes "medical concern for him [the patient] by experienced doctors". ${ }^{83} 84$

The success of technological medicine has made technology the criterion for the demarcation of treatment. ${ }^{85}$ The methods of technological medicine determine what is treatable and thereby set a precedent for what is to be treated. That is, medical technology has become the measure of what is to be treated and what is not to be treated, and hence, what is diseased and what is not. Therapeutically the technologies of corrective surgery, regulating blood pressure and artificial fertilisation have caused health care to treat these conditions as diseases: hypoplastic left heart syndrome, hypertension and infertility. ${ }^{86}$ Decisions and prognosis have come to be based on technology. ${ }^{87-88}$ Furthermore, the possibilities of dialysis and transplantation of kidneys established ESRD as a disease entity. ${ }^{47}$

However, treatability has not only changed the concept of disease by establishing new disease entities. It has also altered existing entities. The ability to detect and treat disease at an early stage has changed the symptoms that patients normally experience and the signs that the doctors relate to the disease. As pointed out earlier, with some diseases the patient never experiences any symptoms at all. Hence, technological treatment alters the course of the disease (perceived by physicians) and the way patients experience it. In this manner technology itself introduces new signs and symptoms that come to constitute the disease. Whereas patients with nephritis earlier experienced diminished urine, swollen legs, nausea and headache, a patient with ESRD is subject to complications of dialysis treatment, such as dialysis-introduced cramps, clotting and infection of catheters and shunts, chronic anaemia, renal bone disease and aluminium toxicity. ${ }^{89}$

Thus, technological treatment influences the concept of disease in a variety of ways. Mitcham elegantly summarises the influence of technology on the basic concepts of medicine:

"Medicine is increasingly defined by the type and character of its instruments (from stethoscope to high-tech imaging devices) and the construction of special human-artefact interactions (synthetic drugs, prosthetic devices). Indeed, the physicianpatient relationship, medical knowledge, and the concept of health are all affected by technological change." 90 
Whether technological treatment is a result of a technological conception of disease or technological treatability strongly influences the concept of disease, the conclusion is the same: technological treatment is basic to the concept of disease. In the former case, the technological concept of disease is established by the pragmatic concern for diagnosis. One applies a technological concept of disease in order to be able to detect the phenomena of disease. In the latter the concept of disease is founded by treatability. However, both diagnosis and treatment are established by technology.

The technological influence of diagnosis and treatment can also be recognised in the way medicine is organised. Disease taxonomy affects the centralisation and specialisation of medicine. ${ }^{91-92}$ This is displayed by the emergence of diagnostic departments, for instance in radiology, nuclear medicine and neurophysiology, and in centres for single technologies such as ultrasound and genetics. Correspondingly, there are therapeutic departments such as chemotherapy, anaesthesiology and dialysis. Hence, there is a technological organisation of diagnosis and treatment of disease.

It has been argued that disease is defined by the methodology of medicine, and that this is constituted by technology. Technology has become the definiens of disease. Because of this constitutive role in medical action, technology has become the paradigm method in medicine. This has influenced the status of disease, which will now be investigated.

\section{The technological status of disease entities}

In practice, technology has become the general method in medicine. Disease can now be measured using objective instruments, ${ }^{93}$ and technology has become the norm for detecting, identifying and treating disease. The success of technology has extended the general belief in technological medicine, enhanced its status and strengthened its paradigmatic position. Technology has become the criterion for the demarcation of what is "rea medicine" and what are "true diseases". "Hightech', hospital-based medicine has been perceived as the acme of medical practice, as against less 'scientific' areas such as primary care ... and psychiatry.",94

In this way technology has not only influenced the concept of disease, but also the status of the disease entities. ${ }^{77}$ Acute high-tech diseases, for example myocardial infarction, enjoy a higher status than chronic low-tech diseases in the same way that heart and brain surgery gain a higher position than geriatrics. Malaria, tuberculosis, and cancer are conceived as clear cases of disease, whereas colour blindness, senility, and depression are vague cases. ${ }^{95}$ In addition, as already noted, whiplash, and fibromyalgia are low-status diseases because they are not technologically detectable or treatable. Thus, there is a technological influence on the status of the disease entities. ${ }^{96}$

\section{Sensitivity, treatment threshold and the technological expansion of disease}

Technology has not only influenced the concept of disease by expanding medical knowledge, as discussed earlier. In practice technology has also expanded the conditions qualifying as disease entities. It has increased the sensitivity to the paraclinical signs and markers.

"The instruments of physics and chemistry, rapidly increasing in sensitivity and complexity, were during the ensuing decades turned to the study of disease. Normal values were determined and deviations from the normal recognized. Hyperchlorhydria and hypochlorhydria, hypertension and hypotension, polycythæmia and anæmia were now capable of recognition and quantitative assessment." 97

This methodological increase in sensitivity seems to be rich in its consequences. It expands the range of conditions qualifying as disease. An example from Copeland can illustrate this point. "As the technical capability of quantifying the nutritional state increases, our power to distinguish mild or borderline cases of hyper- or hypovitaminosis A also increases. The range of normal or healthful levels thus varies according to the level at which we wish to detect deviations from the mean." ${ }^{98}$ Thus, technology increases the sensitivity and enables lower limits of disease. In this manner the technological improvement of medical methods increase the prevalence of disease, ie technology generates disease.

The increase in sensitivity combined with improvements in therapeutic capacity leads to a lowered treatment threshold. This results in an apparent improvement in patient outcome, ${ }^{99}$ and has made technological methods appear highly successful. ${ }^{100}$ This subsequently enhances the constitutive role of technology in defining, in recognising and in treating disease.

\section{Concluding remarks: the technological invention of disease}

All in all it has been argued that technology is constitutive of the concept of disease. Firstly, technology provides the physiological, biochemical, biomolecular and morphological entities that are applied in defining diseases. Secondly, it constitutes the formation of medical knowledge. Technology constitutes the signs, markers and end points that define disease entities and it strongly influences the explanatory models of disease and medical taxonomy. Thirdly, technology establishes how we act towards disease: through diagnosis and treatment technology establishes the actions that constitute disease. Furthermore, the practical capability of technology increases the sensitivity and lowers the treatment threshold, resulting in an increased occurrence of disease.

Hence, medical technology has become the measure of all things; a kind of ars mensura. It has become the technê metriké of the modern age, ${ }^{101}$ the measure of what is good and bad, what is to be 
treated and not, and hence, what is diseased and what is not. This can be entitled the technological invention of disease. What, then, are the consequences of such a "technological concept of disease"?

If the concept of disease is constituted by technology this must be of relevance to the vast, vivid and versatile debate on the concept of disease. The fundamental role of technology will be essential to the debate on the epistemological, ontological and logical status of the concept of disease. Furthermore, it will be of great importance to the debate about the value-ladenness of the concept of disease.

Moreover, the analysis illustrates the importance of paying attention to technology in the general discussion of medicine. Technology, constituting the basic concepts of medicine, its knowledge and its actions, has become essential to the understanding of crucial challenges of modern medicine such as medicalisation, somatisation, paternalism, and patient autonomy. For example, it has been argued that a mechanical conception of disease contributes to paternalistic medical practice due to the reduced role of the patient. ${ }^{102}$ Although these issues are beyond the scope of this article the investigation has made it clear that such challenges are related to the role of technology in medicine.

Furthermore, it is worth noting that the analysis does not presuppose a particular conception of technology. The argument that technology is constitutive to the concept of disease does not depend on a determinist view of medical technology, ${ }^{6} 112088$ 103-104 a phenomenological position, ${ }^{65}$ a social constructivist stance $e^{47} 6^{105-107}$ or on the value-neutral dictum. ${ }^{108}$

The consequences of such a technological concept of disease will depend on the position one takes to technology. The point here has been to argue that within any of these positions technology is constitutive for the concept of disease: Technology has become the measure of disease.

Bjørn Hofmann is a Research Fellow at the University of Oslo, Norway.

\section{References and notes}

1 Boorse C. On the distinction between disease and illness. Philosophy and Public Affairs 1975;5:49-68.

2 Boorse C. Health as a theoretical concept. Philosophy of science 1977;44:542-73

3 Jensen UJ. A critique of essentialism in medicine. In: Nordenfelt L, Lindahl BIB, eds. Health, disease and causal explanation in medicine. Boston: Reidel, 1984: 63-73.

4 Brown WM. On defining "disease". Fournal of Medicine and Philosophy 1985;4:311-28.

5 Hesslow G. Do we need a concept of disease. Theoretical Medicine 1993;14:1-14

6 Jennett B. Medical technology, social and health care issues. In: Gillon R, ed. Principles of health care ethics. New York: John Wiley \& Sons, 1994: 872 .

7 Fabrega H. Scientific usefulness of illness. Perspectives in Biology

8 and Medicine 1979;22:557. experience. Theoretical Medicine 1990;3:227.

9 Evans AS. Causation and disease: effect of technology on posEvans AS. Causation and disease: effect of technology on pos-
tulates of causation. The Yale fournal of Biology and Medicine 1991;64:513-28.
10 A commonplace definition of sign in medicine is that it is an objective piece of evidence of disease, ie such evidence as is perceptible to the examining physician, and which is opposed to the subjective sensations of the patient. A paraclinical sign is objective evidence of disease provided by instrumentation. Wulff HR, Gøtzche PC. Rationel klinik. København: Munksgaard, 1997. The term "indicator" is used widely as synonymous with "sign", and "pathognomic indicators/signs" have been applied as clinical signs. Cohen $\mathrm{H}$. The evolution of the concept of disease. In: Lush B ed. Concepts of medicine: a collection of essays on aspects of medicine. Oxford: Pergamon Press, 1961. Fabrega $\mathrm{H}$. Concepts of disease: logical features and 1961. Fabrega H. Concepts of disease: logical features and social imp

11 Cassell EJ. The sorcerer's broom. Medicine's rampant technology. Hastings Center Report 1993;6:32-9.

12 Copeland DD. Concepts of disease and diagnosis. Perspectives in Biology and Medicine 1977;20:530.

13 Burch GE. Developments in clinical electrocardiography since Einthoven. American Heart fournal 1961;61:324.

14 See reference 10: Cohen H: 163

15 See reference 10: Wulff HR, Gøtzche PC: 110.

16 See reference 10: Wulff HR, Gøtzche PC: 108-9.

17 The application of terms such as "marker" and "risk factor" appears not to be consistent in the literature. Different professions apply them differently.

18 Whittle M. Ultrasonographic "soft markers" of fetal ultrasound. Detecting them may do more harm than good [editorial]. British Medical fournal 1997;314:918.

19 Signs and markers have been denoted soft end points, in contrast to hard end points such as survival and morbidity. We do not feel our blood pressure or cholesterol level.

20 Wolf S, Berle BB. The technological imperative in medicine. London and New York: Plenum Press, 1981.

21 Fagot-Largeault A. On medicine's scientificity-did medicine's accession to scientific "positivity" in the course of the nineteenth century require giving up causal (etiological) explanation? In: Delkeskamp-Hayes C, Cutter MAG, eds. Science, technology and the art of medicine. European-American Dialogues. Dordrecht: Kluwer, 1992:105-26.

22 Juengst ET. Patterns of reasoning in medical genetics. Dordrecht: Kluwer, 1993:143.

23 See reference 22: 144

24 Engelhardt HT. The foundations of bioethics. New York: Oxford University Press, 1986.

25 Engelhardt HT, Wildes KW. Health and disease-philosophical perspectives. In: Reich WT. Encyclopedia of bioethics. New York: MacMillan, 1995: 1103.

26 Susser M. Causal thinking in the health sciences. New York: Oxford University Press, 1973: 14.

27 Jensen UJ. Sygdomsbegreber $i$ praksis: det kliniske arbejdes filosofi og videnskabsteori. København: Munksgaard, 1983: 107.

28 von Engelhardt D. Health and disease-history of the concepts. In: Reich WT ed. Encyclopedia of bioethics. New York: MacMillan, 1995:1088.

29 In the introduction to Leviathan Thomas Hobbes gives a paralel account of man, describing the heart as a spring, the nerves as strings and the joints as wheels. Accordingly Julien Offroy de La Mettrie in L'homme-machine gives an explicit account of man as a machine, which supports René Descartes's clockwork man.

30 Lenihan J. Descartes versus Hippocrates-a conflict resolved? The British fournal of Radiology 1984;57:862.

31 Turner BS. Medical power and social knowledge. London: Sage Publications, 1995: 237.

32 World Health Organization. International statistical classification of diseases and related health problems, IDC-10. Geneva: World of diseases and related health problems,

33 Mitcham C. Thinking through technology. The path between engineering and philosophy. Chicago: The University of Chicago Press, 1994: 35

34 See reference 27: 131

35 Wulff HR, Pedersen SA, Rosenberg R. Medicinsk filosofi. København: Mungsgaard, 1997: 95.

36 Feinstein AR. ICD, POR and DRG. Unsolved scientific problems in the nosology of clinical medicine. Archives of Internal Medicine 1988;148:2269.

37 See reference $35: 92$.

38 Hering HE. Das Elektrocardiogramm des irregularis Perpetuus. Deutsche Archive für klinische Medizin 1908;94:185.

39 See reference 13: 140

40 See reference 28: 1087 .

41 A particular subclass of asymptomatic diseases is called A particular subclass of asymptomatic diseases is called
pseudodiseases. They are asymptomatic diseases that do not develop into illness during the bearer's lifetime. Fischer ES, 
Welch HG. Avoiding the unintended consequences of growth in medical care. Fournal of the American Medical Association 1999;281:446-53.

42 Faber K. Nosography in modern internal medicine. London: Oxford University Press, 1923.

43 Feinstein AR. Clinical judgment. Baltimore: The Williams and Wilkins Company, 1967.

44 Hempel CG. Introduction to problems of taxonomy. In: Zublin J, ed. Field studies in the mental disorders. New York: Grune and Stratton, 1961: 16

45 Scadding JG. Sarcoidosis. London: Eyre \& Spottiswoode, 1967: $877-8$.

46 See reference 13: 324

47 Peitzman SJ. From Bright's disease to end-stage renal disease. In: Rosenberg CE, Golden J, eds. Framing disease: studies in cultural history. New Brunswick NJ: Rutgers University Press, 1992: 3-19.

48 Papaspyros NS. The History of Diabetes Mellitus. Stuttgart: Georg Thieme Verlag, 1964.

49 See reference 44: 18

50 Evans AS. Clinical syndromes in adults caused by respiratory infection. Medical Clinics of North America 1967;51:803-15.

51 Rothman DJ. Beginnings count: the technological imperative in American health care. New York : Oxford University Press, 1997: 45.

52 Temkin O. The scientific approach to disease: specific entity and individual sickness. In: Crombie AC, ed. Scientific change: historical studies in the intellectual, social and technical conditions for scientific discovery and technical invention from antiquity to the present. New York: Basic Books, 1963: 636.

53 Reiser SJ. Medicine and the reign of technology. New York: Cambridge University Press, 1978: 1-90.

54 See reference 53: 91-157.

54 See reference 53: $91-157$

56 English PC. Emergence of rheumatic fever in the nineteenth century. In: Rosenberg CE, Golden J, eds. Framing disease: studies in cultural history. New Brunswick NJ: Rutgers University Press, 1992: 29.

57 See reference 53: 225.

58 See reference 35: 95, 99

59 See reference 11: 34

60 Veatch RM. Against virtue: a deontological critique of virtue theory in medical ethics. In: Shelp EE, ed. Virtue and medicine. Dordrecht: Reidel, 1985: 329-45.

61 Sontag S. Illness as metaphor. New York: Farrar, Strays and Giroux, 1978

62 Blume SS. Insight and industry. On the dynamics of technological change in medicine. Cambridge Mass: The MIT Press, 1992: 36

63 See reference 53:91.

64 See reference 53.228.

65 Cooper MW. The gastroenterologist and his endoscope: The embodiment of technology and the necessity for a medical ethics. Theoretical Medicine 1996;17:394.

66 See reference 47: 9 .

67 Rothman DJ. Strangers at the bedside. History of how law and bioethics transformed medical decision making. New York:

BasicBooks, 1991.

68 See reference 47 McLellan F. "A whole other story": the electro
illness. Literature and Medicine 1997;16:88-107. Redlich FC. Editorial reflections on the concepts of health an disease. Fournal of Medicine and Philosophy 1976;1:275.

71 Engelhardt HT. The concepts of health and disease. In: Engehlardt HT, Spicker SF. Evaluation and explanation in the biomedical sciences. Dordrecht: Reidel, 1975: 137.

72 Campbell EJ, Scadding JG, Roberts RS. The concept of disease. British Medical fournal 1979;2:757-62.

73 Anonymous [editorial]. The concept of disease. British Medical fournal 1979; 6193: 751 .

74 See reference 62:21.

75 "An operational definition of a scientific term $S$ is a stipulation to the effect that $S$ is to apply to all and only those cases for which performance of test operation $T$ yields the specific outwhich performance of test operation T yields the specific outcome O." Bridgman

76 See reference 62: 48

77 Album D. The prestige of diseases and medical specialities. Tidsskr Nor Lageforen 1991;111:2127-33.
78 Technology is not only constitutive of diagnosis and treatment, but plays an important role in palliation as well. Rognum TO ["Home monitoring" does not prevent crib death. Managing possibilities and results of new technology] Tidsskr Nor Laegeforen 1995;115:2790-3.

79 See reference 28: 1085

80 See reference 5: 7 .

81 Kennedy I. The unmasking of medicine. London:Allen and Unwin, 1981: 25

82 Taylor FK. A logical analysis of the medico-psychological concept of disease. Psychological Medicine 1971;1:356-64; 1971;2: $7-16$.

83 Taylor FK. Disease concepts and the logic of classes. British Fournal of Medical Psychology 1981;54:284.

84 Taylor FK. A logical analysis of disease concepts. Comprehensive Psychiatry 1983;24:47.

85 See reference $4: 317$.

86 Le Fanu points out that the laparascope facilitated the treatment of infertility, and thereby established it as a disease. (Le Fanu J. The rise and fall of modern medicine. London: Little Brown, 1999: 159.) Correspondingly, chlorothiazide and propanolol established hypertension as a disease (page128-38).

87 Anspach RR. Prognostic conflict in life-and death decisions: the organization as an ecology of knowledge. Fournal of Health and Social Behavior 1987;28:215-31.

88 Tymstra T. The imperative character of medical technology and the meaning of "anticipated decision regret". International fournal of Technology Assessment in health Care 1989;5:207-13.

89 See reference 47: 15.

90 Mitcham C. Philosophy of technology. In: Reich WT, ed. Encyclopedia of bioethics. New York: MacMillan, 1995: 2477

91 See reference 53: 144-58.

92 See reference 81: 22 .

93 Twaddle A. Disease, illness and sickness revisited. In: Twaddle A, Nordenfelt L. Disease, illness and sickness: three central concept in the theory of health. Linköping: Department of Health and Society, 1993: 9 .

94 Fulford KWM. Praxis makes perfect: illness as a bridge between biological concepts of disease and social conceptions of health. Theoretical Medicine 1993;14:309.

95 See reference $72: 759$.

96 This paradigmatic position of technology in medicine has been criticised. It has been argued that technology is applied prior to a proper evaluation of its outcome. Its application has been criticised as excessive by llich and Davidson and as futile, by Fisher et al. Illich I. Medical nemesis: the expropriation of health. London: Calder and Boyars, 1975; Davidson SN. Technological cancer: its causes and treatment. Healthcare Forum fournal 1995;38:52-58. Fischer ES, Welch HG, Schneidermann LJ, Jecker NS. Wrong medicine: doctors, patients and futile treatment. Baltimore: Johns Hopkins, 1995.

97 See reference 10: Cohen $\mathrm{H}$ : 167.

98 See reference 12: 530-1.

99 See reference 41: Fischer ES, Welch HG: 449.

100 Feinstein AR, Sosin DM, Wells CK. The Will Rogers phenomenon: stage migration and new diagnostic techniques as a source of misleading statistics for survival in cancer. $N$ ew England fournal of Medicine 1985;312:1604-8.

101 Plato Gorgias 356d4-e2.

102 See reference 10: Wulff HR, Gøtzche PC.

03 Ellul J. The technological society. New York: Alfred A Knopf, 1964.

104 Winner L. Autonomous technology. Cambridge Ma: MIT Press, 1977.

105 Rosenberg CE. Framing disease: illness, society, and history. In: Rosenberg CE, Golden J, eds. Framing disease: studies in cultural history. New Brunswick NJ: Rutgers University Press, 1992: xiii-xxvi

106 Bennett IL. Technology as a shaping force. In: Knowles JH, ed. Doing better and feeling worse. New York: Norton \& Co, 1977: 125-33.

107 Barley SB. The social construction of a machine: ritual, superstition, magical thinking and other pragmatic responses to
running a CT skanner. In Lock M, Godon DR, eds. running a CT skanner. In Lock M, Godon DR,
Biomedicine examined. Dordrecht: Kluwer, 1988: 497-539.

108 Sundström P. Interpreting the notion that technology is value-neutral. Medicine, Health Care and Philosophy 1998;1:41-5. 